\title{
REFORMAS E REALIDADE o caso do ensino das ciências
}

\author{
Myriam Krasilchik \\ Professora da Faculdade de Educação da Universidade de São Paulo
}

\begin{abstract}
Resumo: Este trabalho inclui uma revisão histórica das propostas de reforma do ensino de Ciências ao longo dos últimos anos. O caso descrito ilustra alguns dos caminhos percorridos por vários projetos desde a sua elaboração nos órgãos normativos como parte de políticas públicas até o dia-a-dia das salas de aula. A análise do processo compreendendo aspectos legais, modalidades e recursos didáticos, temáticas dos programas, e processos de avaliação contribui para o estudo de propostas de inovação.

Palavras-chave: reforma educacional; didática e ensino das ciências; avaliação e pesquisa.
\end{abstract}

A palavra reforma, sempre presente no vocabulário educacional, é definida em âmbito internacional como "uma iniciativa do Estado que estabelece objetivos e critérios claros e ambiciosos, recorre a todas as instâncias políticas para apoiá-la, estimulando iniciativas no nível das escolas e mobilizando recursos humanos e financeiros para sustentar as mudanças propostas" (Timpane e White, 1998).

Nossas escolas, como sempre, refletem as maiores mudanças na sociedade - política, econômica, social e culturalmente. A cada novo governo ocorre um surto reformista que atinge principalmente os ensinos básico e médio. $\mathrm{O}$ atual movimento de reforma da escola é um processo de mudança nacional com uma forte tendência à volta ao papel centralizador do Estado para emissão de normas e regulamentos.

Tomando como marco inicial a década de 50, é possível reconhecer nestes últimos 50 anos movimentos que refletem diferentes objetivos da educação modificados evolutivamente em função de transformações no âmbito da política e economia, tanto nacional como internacional.

Na medida em que a Ciência e a Tecnologia foram reconhecidas como essenciais no desenvolvimento econômico, cultural e social, o ensino das Ciências em todos os níveis foi também crescendo de importância, sendo objeto de inúmeros movimentos de transformação do ensino, podendo servir de ilustração para tentativas e efeitos das reformas educacionais.

Um episódio muito significativo ocorreu durante a "guerra fria", nos anos 60, quando os Estados Unidos, para vencer a batalha espacial, fizeram investimentos de recursos humanos e financeiros sem paralelo na história da educação, para produzir os hoje chamados projetos de 1aㅡ geração do ensino de Física, Química, Biologia e Matemática para o ensino médio. A justificativa desse empreendimento baseava-se na idéia de que a formação de uma elite que garantisse a hegemonia norte-americana na conquista do espaço dependia, em boa parte, de uma escola secundária em que os cursos das Ciências identificassem e incentivassem jovens talentos a seguir carreiras científicas.

Esse movimento, que teve a participação intensa das sociedades científicas, das Universidades e de acadêmicos renomados, apoiados pelo governo, elaboraram o que também é denominado na literatura especializada de "sopa alfabética", uma vez que os projetos de Física (Physical Science Study Commitee - PSSC), de Biologia (Biological Science Curriculum Study - BSCS), de Química (Chemical Bond Approach - CBA) e (Science Mathematics Study Group SMSG) são conhecidos universalmente pelas suas siglas.

Esse período marcante e crucial na história do ensino de Ciências, que influi até hoje nas tendências curriculares das várias disciplinas tanto no ensino médio como no 
QUADRO 1

Evolução da Situação Mundial, segundo Tendências no Ensino

$1950-2000$

\begin{tabular}{|c|c|c|c|}
\hline \multirow{3}{*}{$\begin{array}{l}\text { Tendências no } \\
\text { Ensino }\end{array}$} & \multicolumn{3}{|c|}{ Situação Mundial } \\
\hline & 1950 & 1970 & 1990 \\
\hline & Guerra Fria & Guerra Tecnológica & Globalização \\
\hline Objetivo do Ensino & $\begin{array}{l}\text { - Formar Elite } \\
\text { - Programas Rígidos }\end{array}$ & $\begin{array}{l}\text { - Formar Cidadão-trabalhador } \\
\text { - Propostas Curriculares Estaduais }\end{array}$ & $\begin{array}{l}\text { - Formar Cidadão-trabalhador-estudante } \\
\text { - Parâmetros Curriculares Federais }\end{array}$ \\
\hline Concepção de Ciência & - Atividade Neutra & $\begin{array}{l}\text { - Evolução Histórica } \\
\text { - Pensamento Lógico-crítico }\end{array}$ & - Atividade com Implicações Sociais \\
\hline Instituições Promotoras de Reforma & $\begin{array}{l}\text { - Projetos Curriculares } \\
\text { - Associações Profissionais }\end{array}$ & - Centros de Ciências, Universidades & - Universidades e Associações Profissionais \\
\hline Modalidades Didáticas Recomendadas & - Aulas Práticas & - Projetos e Discussões & - Jogos: Exercícios no Computador \\
\hline
\end{tabular}

Fonte: Elaboração da autora.

fundamental, foi dando lugar, ao longo dessas últimas décadas, a outras modificações em função de fatores políticos, econômicos e sociais que resultaram, por sua vez, em transformações das políticas educacionais, cumulativas em função das quais ocorreram mudanças no ensino de Ciências (Quadro 1).

Como já foi mencionado, o movimento dos grandes projetos visava a formação e a identificação de uma elite refletindo não só a política governamental, mas também uma concepção de escola e teve propagação ampla nas regiões sob influência cultural norte-americana, que repercutiu de forma diferente em diversos países ecoando as situações locais. Por exemplo, na Inglaterra, concordou-se com os objetivos gerais do projeto de reforma do ensino de Ciências, mas foi decidido que se devia produzir seus próprios projetos consonantes com a organização escolar de forma a preservar a influência acadêmica e científica de instituições inglesas. Foram elaborados também projetos de Física, Química e Biologia que ficaram conhecidos pelo nome da sua instituição patrocinadora, a Fundação Nuffield. Dada a importância da Inglaterra como núcleo cultural dos países da comunidade britânica, esses projetos tiveram também grande influência.

No Brasil, a necessidade de preparação dos alunos mais aptos era defendida em nome da demanda de investigadores para impulsionar o progresso da ciência e tecnologia nacionais das quais dependia o país em processo de industrialização. A sociedade brasileira, que se ressentia da falta de matéria-prima e produtos industrializados durante a $2^{\mathrm{a}}$ Guerra Mundial e no período pós-guerra, buscava superar a dependência e se tornar auto-suficiente, para o que uma ciência autóctone era fundamental.

Paralelamente, à medida que o país foi passando por transformações políticas em um breve período de eleições livres, houve uma mudança na concepção do papel da escola que passava a ser responsável pela formação de todos os cidadãos e não mais apenas de um grupo privilegiado. A Lei 4.024 - Diretrizes e Bases da Educação, de 21 de dezembro de 1961, ampliou bastante a participação das ciências no currículo escolar, que passaram a figurar desde o 1 o ano do curso ginasial. No curso colegial, houve também substancial aumento da carga horária de Física, Química e Biologia.

Essas disciplinas passavam a ter a função de desenvolver o espírito crítico com o exercício do método científico. O cidadão seria preparado para pensar lógica e criticamente e assim capaz de tomar decisões com base em informações e dados.

Quando de novo houve transformações políticas no país pela imposição da ditadura militar em 1964, também o papel da escola modificou-se, deixando de enfatizar a cidadania para buscar a formação do trabalhador, considerado agora peça importante para o desenvolvimento econômico do país. A Lei de Diretrizes e Bases da Educação no 5.692, promulgada em 1971, norteia claramente as modificações educacionais e, conseqüentemente, as propostas de reforma no ensino de Ciências ocorridas neste 
período. Mais uma vez as disciplinas científicas foram afetadas, agora de forma adversa, pois passaram a ter caráter profissionalizante, descaracterizando sua função no currículo. A nova legislação conturbou o sistema, mas as escolas privadas continuaram a preparar seus alunos para o curso superior e o sistema público também se reajustou de modo a abandonar as pretensões irrealistas de formação profissional no $1^{\circ}$ e $2^{\underline{o}}$ graus por meio de disciplinas pretensamente preparatórias para o trabalho.

Em 1996, foi aprovada uma nova Lei de Diretrizes e Bases da Educação, no 9.394/96, a qual estabelece, no parágrafo $2^{\circ}$ do seu artigo $1^{\circ}$, que a educação escolar deverá vincular-se ao mundo do trabalho e à prática social. $\mathrm{O}$ artigo 26 estabelece que "os currículos do ensino fundamental e médio devem ter uma base nacional comum, a ser complementada pelos demais conteúdos curriculares especificados nesta Lei e em cada sistema de ensino". A formação básica do cidadão na escola fundamental exige o pleno domínio da leitura, da escrita e do cálculo, a compreensão do ambiente material e social, do sistema político, da tecnologia, das artes e dos valores em que se fundamenta a sociedade. $\mathrm{O}$ ensino médio tem a função de consolidação dos conhecimentos e a preparação para o trabalho e a cidadania para continuar aprendendo.

Esse aprendizado inclui a formação ética, a autonomia intelectual e a compreensão dos fundamentos científicotecnológicos dos processos produtivos. Embora a lei indique precariamente os valores e objetivos da educação nacional, espera-se que a escola forme o cidadão-trabalhador-estudante quando, por exemplo, determina em seu artigo 80: "O Poder Público incentivará o desenvolvimento e a veiculação de programas de ensino a distância, em todos os níveis e modalidades de ensino, e de educação continuada."

Tenta-se colocar em prática essas prescrições legais por meio de políticas centralizadas no MEC e que são detalhadas e especificadas em documentos oficias, abundantemente distribuídos com os nomes de "parâmetros" e "diretrizes curriculares". Fazem parte ainda desses "indicativos políticos" diversos instrumentos de avaliação em que se explicitam as reais intenções da reforma proposta pelo governo.

No exame dessa proposta e de suas conseqüências na realidade da educação brasileira, é imprescindível analisar em uma perspectiva histórica a evolução das concepções curriculares preponderantes nesses últimos 50 anos, por meio dos quais foram expressos os desígnios dos governos e seus resultados nos vários níveis dos sistemas educacionais, desde o emissor das políticas até a realidade das salas de aula, que têm mudado muito mais em função da deterioração das condições de trabalho do que por injunções legais. Infelizmente, mantém-se um ensino precário com professores que enfrentam nas escolas problemas de sobrecarga, de falta de recursos e de determinações que deveriam seguir sobre as quais não foram ouvidos.

As modificações promovidas por diferentes elementos ao longo dos diversos patamares de decisões que atuam nos componentes curriculares - temáticas e conteúdo, modalidades didáticas e recursos e processos de avaliação - confluem para um cenário que raramente é o planejado pelos emissores do currículo teórico.

$\mathrm{Na}$ análise desse processo, tem papel fundamental a pesquisa feita no âmbito do ensino das ciências no Brasil e que já constitui um significativo acervo de informações e conhecimentos sobre o que acontece desde a elaboração de documentos normativos até a intimidade do ensino das várias disciplinas científicas.

\section{MODALIDADES DIDÁTICAS E RECURSOS}

As modalidades didáticas usadas no ensino das disciplinas científicas dependem, fundamentalmente, da concepção de aprendizagem de Ciência adotada. A tendência de currículos tradicionalistas ou racionalistasacadêmicos, apesar de todas as mudanças, ainda prevalecem não só no Brasil, mas também nos sistemas educacionais de países em vários níveis de desenvolvimento. Assumindo que o objetivo dos cursos é basicamente transmitir informação, ao professor cabe apresentar a matéria de forma atualizada e organizada, facilitando a aquisição de conhecimentos. Nos anos 60 , o processo ensino-aprendizagem era influenciado pelas idéias de educadores comportamentalistas que recomendavam a apresentação de objetivos do ensino na forma de comportamentos observáveis, indicando formas de atingi-los e indicadores mínimos de desempenho aceitável. Foram elaboradas classificações, das quais a mais conhecida, coordenada por Benjamim Bloom, era a que dividia os objetivos educacionais em cognitivo-intelectuais, afetivo-emocionais e psicomotores-habilidades, organizados em escalas hierarquicamente mais complexas de comportamento.

Essa linha de trabalho teve papel significativo na educação brasileira e ainda hoje muitos dos processos de planejamento que ocorrem nas escolas constam apenas da redação de objetivos e metas, que em geral são esqueci- 
dos durante o ano por força da pressão das realidades do dia-a-dia na classe.

No final dos anos 60, as idéias de Jean Piaget sobre desenvolvimento intelectual começaram a ser conhecidas e discutidas. Passa assim a ter papel central no processo ensino-aprendizagem da ciência uma perspectiva cognitivista, enfatizando o chamado construtivismo, usado nos atuais documentos oficiais brasileiros de forma impositiva, como um "slogan" que não chega a analisar o significado da discussão sobre mudança conceitual como um processo individual de responsabilidade do aluno ou um processo social. "A primeira perspectiva vê concepções como representações mentais (isto é, construções tangíveis na cabeça dos alunos) enquanto a segunda perspectiva representa as concepções como sendo caracterizações de categorias de descrições que refletem relações pessoamundo" (Duit e Treagust, 1998).

Essas idéias conflitantes em vários aspectos não são apresentadas aos professores como controvérsias que devem ser discutidas e analisadas para orientar a escolha de modalidades didáticas baseadas em uma fundamentação sólida.

Embora o conceito de processo ensino-aprendizagem tenha importância na escola em geral, no ensino das disciplinas científicas tem conseqüências específicas em vários elementos curriculares. A solução de problemas é um dos seus componentes essenciais, porque várias fases das reformas propostas com nomes variados de "ciência posta em prática", "método da redescoberta", "método de projetos" trata-se de fazer questionamentos, encontrar alternativas de resposta, planejar e organizar experimentos que permitam optar por uma delas e daí produzir outros questionamentos. No período 1950-70, prevaleceu a idéia da existência de uma seqüência fixa e básica de comportamentos, que caracterizaria o método científico na identificação de problemas, elaboração de hipóteses e verificação experimental dessas hipóteses, o que permitiria chegar a uma conclusão e levantar novas questões.

Com essas premissas, as aulas práticas no ensino de Ciências servem a diferentes funções para diversas concepções do papel da escola e da forma de aprendizagem. No caso de um currículo que focaliza primordialmente a transmissão de informações, o trabalho em laboratório é motivador da aprendizagem, levando ao desenvolvimento de habilidades técnicas e principalmente auxiliando a fixação, o conhecimento sobre os fenômenos e fatos.

À medida que a influência cognitivista foi se ampliando em base dos estudos piagetianos considerando fases de operações lógicas pelas quais o aluno passa em uma ordem que vai do sensomotor (18 meses), pré-operacional (até 7 anos), concreta operacional (dos 7 aos 11 anos) até o formal operacional (dos 11 até os 15 anos), passouse a encarar o laboratório como elemento de aferição do estágio de desenvolvimento do aluno e de ativação do progresso ao longo desses estágios e do ciclo de aprendizado.

$\mathrm{Na}$ perspectiva construtivista, as pré-concepções dos alunos sobre os fenômenos e sua atuação nas aulas práticas são férteis fontes de investigação para os pesquisadores como elucidação do que pensam e como é possível fazê-los progredir no raciocínio e análise dos fenômenos. As prescrições oficiais da expectativa de reforma em curso tratam do assunto superficialmente, havendo uma grande distância entre uma "proposta construtivista" e recomendações que permitam ao professor exercer plenamente o seu papel de catalisador da aprendizagem. Faltam discussões que permitam ao próprio docente nas atuais condições de trabalho criar um clima de liberdade intelectual, que não limite a sua atividade a exposições, leitura ou cópia de textos.

Por exemplo, a reação de alunos e professores ao uso de perguntas em classe é uma área de pesquisa de ponta para os que pretendem mudar a escola e o ensino de Ciências em que a função da interação social e da exposição a diferentes idéias é elemento essencial. Como obstáculo a essa transformação, é possível identificar as representações sociais que prevalecem entre professor e alunos. $\mathrm{O}$ docente é autoridade que não corre o risco de ser questionada, ou que se permita ouvir diferentes opiniões. Se, por um lado, esse papel autoritário é prejudicial, o outro extremo cada vez mais freqüente por força do refrão de que o "aluno constrói seu próprio conhecimento" leva o professor a abdicar da sua função de orientador do aprendizado. Nesses casos, o laboratório e as aulas práticas podem até ser divertidas mas não levam à formulação ou reformulação de conceitos.

Os novos recursos tecnológicos e, principalmente, o uso do computador criam dilemas equivalentes, podendo até ser uma fonte muito eficiente de fornecimento de informações. No entanto, o seu potencial como desequilibrador da vigente relação professor-aluno é ainda subutilizado como instrumento que possa levar o aluno a deixar o seu papel passivo de receptor de informações, para ser o que busca, integra, cria novas informações. $\mathrm{O}$ professor passa a ser o que auxilia o aprendiz a procurar e coordenar o que aprende dentro de um esquema conceitual mais amplo. Qualquer reforma deveria suscitar essas 
questões que são básicas para uma mudança real na qualidade de ensino.

\section{TEMÁTICAS}

Os conteúdos e grandes temas incluídos no currículo das disciplinas científicas refletem as idéias correntes sobre a Ciência. Na fase dos projetos de $1^{\mathbf{a}}$ geração, a Ciência era considerada uma atividade neutra, isentando os pesquisadores de julgamento de valores sobre o que estavam fazendo. É necessário lembrar que os cientistas tiveram uma atuação significativa na produção da bomba atômica e, de alguma forma, procuravam não assumir sua responsabilidade no conflito bélico. Pretendia-se desenvolver a racionalidade, a capacidade de fazer observações controladas, preparar e analisar estatísticas, respeitar a exigência de replicabilidade dos experimentos.

À medida que se avolumaram os problemas sociais no mundo, outros valores e outras temáticas foram incorporadas aos currículos, sendo que mudanças substantivas tiveram repercussões nos programas vigentes. Entre 1960 e 1980, as crises ambientais, o aumento da poluição, a crise energética e a efervescência social manifestada em movimentos como a revolta estudantil e as lutas anti-segregação racial determinaram profundas transformações nas propostas das disciplinas científicas em todos os níveis do ensino.

As implicações sociais da Ciência incorporam-se às propostas curriculares nos cursos ginasiais da época e, em seguida, nos cursos primários. Simultaneamente às transformações políticas ocorreu a expansão do ensino público que não mais pretendia formar cientistas, mas também fornecer ao cidadão elementos para viver melhor e participar do breve processo de redemocratização ocorrido no período. A admissão das conexões entre a ciência e a sociedade implica que o ensino não se limite aos aspectos internos à investigação científica, mas à correlação destes com aspectos políticos, econômicos e culturais. Os alunos passam a estudar conteúdos científicos relevantes para sua vida, no sentido de identificar os problemas e buscar soluções para os mesmos. Surgem projetos que incluem temáticas como poluição, lixo, fontes de energia, economia de recursos naturais, crescimento populacional, demandando tratamento interdisciplinar. Essas demandas dependiam tanto dos temas abordados como da organização escolar. É do período de 1950-70 o movimento de Ciência Integrada, que teve apoio de organismos internacionais, principalmente a Unesco, e provocou reações adversas dos que defendiam a identidade das disciplinas tradicionais, mantendo segmentação de conteúdos mesmo nos anos iniciais da escolaridade.

Concomitantemente aos processos que ocorriam nas escolas - o fim da "guerra fria" e o agravamento dos problemas sociais e econômicos - foi incorporada a competição tecnológica, levando a exigir que os estudantes tivessem preparo para compreender a natureza, o significado e a importância da tecnologia para sua vida como indivíduos e como membros responsáveis da sociedade. Para tanto, os cursos deveriam incluir temas relevantes que tornassem os alunos conscientes de suas responsabilidades como cidadãos, pudessem participar de forma inteligente e informada de decisões que iriam afetar não só sua comunidade mais próxima, mas que também teriam efeitos de amplo alcance.

A preocupação com a qualidade da "escola para todos" incluiu um novo componente no vocabulário e nas preocupações dos educadores, "a alfabetização científica". A relação ciência e sociedade provocou a intensificação de estudos da história e filosofia da ciência, componentes sempre presentes nos programas com maior ou menor intensidade servindo em fases diferentes a objetivos diversos. $\mathrm{O}$ crescimento da influência construtivista como geradora de diretrizes para o ensino levou à maior inclusão de tópicos de história e filosofia da Ciência nos programas, principalmente para comparar linhas de raciocínio historicamente desenvolvidas pelos cientistas e as concepções dos alunos.

Fortalece essa linha o já mencionado movimento denominado "Ciência para todos", que relaciona o ensino das Ciências à vida diária e experiência dos estudantes, trazendo, por sua vez, novas exigências para compreensão da interação estreita e complexa com problemas éticos, religiosos, ideológicos, culturais, étnicos e as relações com o mundo interligado por sistemas de comunicação e tecnologias cada vez mais eficientes com benefícios e riscos no globalizado mundo atual. A exclusão social, a luta pelos direitos humanos e a conquista da melhora da qualidade de vida não podem ficar à margem dos currículos e, no momento, assumem uma importância cada vez mais evidente. Pela demanda de justiça social nos atuais parâmetros curriculares, muitas das temáticas vinculadas no ensino de Ciências são hoje consideradas "temas transversais": educação ambiental, saúde, educação sexual. No entanto, a tradição escolar ainda determina que a responsabilidade do seu ensino recaia basicamente nas disciplinas científicas, principalmente a Biologia. 
A reforma brasileira reforça um movimento equivalente ao da "Ciência para todos", sem, no entanto, incluir cuidados para que excessos nessa postura tornem o currículo pouco rigoroso, em nome da necessidade que se tornou um estribilho nas publicações e avaliações oficiais de desenvolver "competências e habilidades".

O risco grave é de que se percam de vista os objetivos maiores do ensino de Ciências, que deve incluir a aquisição do conhecimento científico por uma população que compreenda e valorize a Ciência como empreendimento social. Os alunos não serão adequadamente formados se não correlacionarem as disciplinas escolares com a atividade científica e tecnológica e os problemas sociais contemporâneos. Paralelamente aos movimentos nas instâncias normativas dos sistemas escolares, os livros didáticos continuaram a servir de apoio e orientação aos professores para a apresentação dos conteúdos. Uma reforma que tenha pleno êxito depende da existência de bons materiais, incluindo livros, manuais de laboratórios e guias de professores, docentes que sejam capazes de usá-los, bem como condições na escola para o seu pleno desenvolvimento.

\section{Avaliação}

A avaliação sempre teve um papel central na escola brasileira. Uma das influências preeminentes, com uma função normativa mais poderosa do que os programas oficiais, livros didáticos, propostas curriculares ou os atuais parâmetros, sempre foi o exame vestibular. Assim, essas provas, mais do que cumprir a função classificatória para decidir quais os alunos que podem entrar nas escolas superiores, têm grande influência nos ensinos fundamental e médio. No entanto, os exames podem fornecer dados sobre a população escolar cumprindo a maior função da avaliação, ou seja, a de informar à sociedade, às escolas, aos alunos, aos professores e aos pais sobre o aprendizado dos estudantes, da eficiência da escola em função das políticas públicas e das relações contextuais entre os estabelecimentos de ensino e a comunidade nas quais se situam.

Com a democratização do país e a disputa por verbas para manutenção dos sistemas escolares, aumenta a pressão por dados que possam servir de indicadores que orientem decisões dos sistemas em todos o níveis de ensino.

A competição internacional na guerra tecnológica produziu programas internacionais de avaliação que levaram à comparação do resultado obtido pelos alunos em algumas disciplinas, incluindo as Ciências. Assim como o
Sputnik provocou movimento de reforma dos anos 60 , o desempenho dos alunos norte-americanos nos testes internacionais produziu em 1985 um documento de grande impacto "A Nation at Risk" que serviu de epicentro para uma onda de críticas ao sistema educacional norte-americano e tentativas de reformas que acabaram tendo repercussões no mundo inteiro (Gross e Gross, 1985).

No Brasil, é parte das políticas governamentais no plano federal ou estaduais um conjunto de exames que se destinam a descrever a situação nas várias unidades da federação, no sentido de subsidiar decisões de políticas públicas. Instituições internacionais como o Banco Mundial, Banco Interamericano e a Unesco valem-se desses indicadores para fomentar e financiar projetos que implementem tendências que apóiam.

$\mathrm{O}$ resultado e a validade desses exames para avaliar o aprendizado em Ciências são bastante contestados em função dos instrumentos que os constituem. Discute-se se as tradicionais questões de múltipla escolha são adequadas para aferir o que se pretende produzir dos alunos nas aulas de Ciências. A capacidade de resolver problemas e de demonstrar a compreensão conceitual e formação exige que se busquem também outras formas de verificar o aprendizado. Assim, provas dissertativas e redações teriam como função maior fazer com que os alunos escrevam, demonstrando capacidade de organização lógica e de expressão temática.

O reconhecimento das limitações dos instrumentos de avaliação mais freqüentemente usados não impede, no entanto, que os dados numéricos sejam divulgados como resultados confiáveis, exercendo considerável influência na opinião que a sociedade tem da escola. Os meios de comunicação de massa divulgam esses números com interpretações que, muitas vezes, exigem análises mais detidas, mas são aceitos sem discussão pela população em geral, tornando premente a necessidade de uma coleta sistemática de informações coerentes das variáveis que agem no aprendizado de Ciências e que refletiram os objetivos do currículo. Busca-se, assim, distinguir as diferenças entre o currículo proposto, ideal, teórico e o seu resultado, ou seja, o currículo real ou obtido.

Por exemplo, na avaliação dos concluintes do ensino médio feita em 1997 em nove estados brasileiros, verifica-se que em Biologia os alunos do período da manhã acertaram menos de $47 \%$ das questões, os da tarde, 35,5\%, e os da noite, $29 \%$. Em Física, foram $33 \%$ de acertos para os alunos da manhã, $28 \%$ para os da tarde e $27,5 \%$ para os da noite. Química evidenciou problemas com relação 
a todos os conteúdos e habilidades. Os alunos da manhã tiveram $33 \%$ de acertos, os da tarde, $27,5 \%$, e os da noite, $25 \%$. Apesar das pequenas variações e diferenças nos turnos examinados, o desempenho dos alunos deixa muito a desejar.

O Sistema Nacional de Educação Básica - Saeb (1997) e o Instituto Nacional de Pesquisas e Estudos Educacionais - Inep (1999) indicam que, nas séries iniciais, em Ciências, os alunos até a $4^{\mathrm{a}}$ série saem-se bem. Nos outros níveis, o desempenho esperado de alunos de $6^{\underline{a}}$ série chega a ser atingido por $48 \%$ dos alunos, na $8^{\mathrm{a}}$ série por $10 \%$ e, no fim do ensino médio, apenas $3 \%$ alcançam o nível desejado. Como se pode verificar por esses dados, há uma grande distância entre as propostas de reforma e o resultado efetivo no aprendizado dos alunos.

\section{Pesquisa}

As discussões sobre o ensino de Ciências e tentativa de transformá-lo foram promovidas e mantidas por inúmeras e diversas instituições a partir dos "projetos curriculares" organizados nos anos 60. Na época, o Brasil já tinha uma história de promoção do ensino de Ciências o IBECC (Instituto Brasileiro de Educação, Ciência e Cultura) em São Paulo, em que eram produzidos manuais de laboratórios e textos, além de equipamentos para a experimentação.

Muitos trabalhos esparsos de iniciativas de docentes isolados ou em grupos passaram a se concentrar no IBECC e depois em instituições dele derivadas - Funbec e Cecisp -, que, com o apoio do Ministério da Educação, das Fundações Ford e Rockfeller e da União Panamericana, promoveram intensos programas para a renovação do ensino de Ciências. Especialmente significativa foi a iniciativa do MEC, que criou em 1963 seis centros de ciências nas maiores capitais brasileiras: São Paulo, Rio de Janeiro, Salvador, Recife, Porto Alegre e Belo Horizonte. A estrutura institucional desses centros era variada. Alguns, como o de Porto Alegre e Rio de Janeiro, tinham vínculos com Secretarias de Governo da Educação e de Ciência e Tecnologia, enquanto os de São Paulo, Pernambuco, Bahia e Minas Gerais eram ligados às Universidades. Essas instituições tiveram vidas e vocações diferentes, sendo que algumas persistem até hoje, como a de Belo Horizonte, estreitamente associada à Faculdade de Educação da UFMG, e o centro do Rio, que hoje é mantido pela Secretaria da Ciência e Tecnologia. Os outros ou desapareceram ou foram incorporados pelas universidades onde pas- saram a se estruturar grupos de professores para preparar materiais e realizar pesquisas sobre o ensino de ciências. Com a expansão dos programas de pós-graduação e delineamento de uma área específica de pesquisa - Ensino de Ciências -, as organizações acadêmicas assumiram a responsabilidade de investigar e procurar fatores e situações que melhorassem os processos de ensino-aprendizado.

Esse movimento ocorre agora nos Centros de Ciências ou nas Universidades e ganha atenção das autoridades federais e instituições internacionais, estabelecendo programas como o Premem (Projeto de Melhoria do Ensino de Ciências e Matemática) e o SPEC (Subprograma de Educação para a Ciência), vinculado à Capes (Fundação Coordenação de Aperfeiçoamento de Pessoal de Nível Superior) e mais recentemente o pró-Ciências e os programas de educação científica e ambiental do $\mathrm{CNPq}$ (Conselho Nacional de Desenvolvimento Científico e Tecnológico).

No plano internacional o processo foi equivalente. Os núcleos catalisadores dos movimentos dos anos 60 foram incorporados pelas universidades. Alguns centros permanecem como o Biological Science Curriculum Study, que até hoje está produzindo inovações no ensino de Biologia.

Nos Estados Unidos foram importantes as sociedades científicas ao longo das décadas consideradas neste trabalho, especialmente a American Association for the Advancement of Science - AAAS, que teve persistente preocupação com o ensino elaborando seus próprios projetos curriculares. Nos anos 70, influenciada pelas tendências comportamentalistas proeminentes na época, preparou material para ensino de Ciências para crianças de escola primária. Hoje está conduzindo o chamado Project 2061, que reúne cientistas e educadores no sentido de estabelecer o que "todos os estudantes devem saber ou fazer em ciência, matemática e tecnologia desde os primeiros anos de estudo até o final do curso médio, de modo a promover a sua 'alfabetização científica" (AAAS, 1989). Outras associações científicas, como a Unesco e a International Council of Scientific Unions - ICSU, além das sociedades internacionais de Física, Química e Matemática, realizam reuniões e promovem atividades visando o desenvolvimento do ensino de Ciências.

No Brasil, sociedades como a SBF (Sociedade Brasileira de Física), a SBQ (Sociedade Brasileira de Química) e a SBG (Sociedade Brasileira de Genética) têm atividades relacionadas ao ensino. A Associação Brasileira para Pesquisa em Ensino de Ciências e a Sociedade Brasileira para o Ensino de Biologia reúnem juntam centenas de professores dos ensinos fundamental, médio e superior 
para discutir problemas, apresentar trabalhos e atualizar informações.

Incorporam-se também ao movimento de renovação instituições como museus de ciências que estabelecem pontes com um público preponderantemente, mas não exclusivamente, escolar a quem apresentam a ciência por meio de exposições e outras instalações interativas.

Há intensa atividade de investigação nos cursos de pósgraduação, acumulando um considerável acervo de conhecimento. Investigações sobre as relações professoralunos, enfatizando vários aspectos do trabalho em laboratório, discussão de problemas e o papel das perguntas em classe, efeito de atividades para aperfeiçoamento de professores na mudança de atitude e aquisição de conhecimentos e o papel dos centros e museus da Ciência são algumas das questões em que os mestrandos e doutorandos vêm trabalhando.

A pesquisa em ensino de Ciências levou também à formação de grupos interdisciplinares, congregando professores de institutos de Física, Química, Biologia e das Faculdades e Centros de Educação. O primeiro programa de mestrado em ensino de Ciências interunidades que subsiste até hoje foi instalado na Universidade de São Paulo, em que a partir dessa iniciativa formaram-se grupos de ensino nos Institutos de Física e Química, além do desenvolvimento de uma área temática de Ensino de Ciências e Matemática para mestrado e doutorado na Faculdade de Educação.

Assim como ocorreram mudanças nos objetivos e ênfase das propostas curriculares, também a pesquisa foi evoluindo no transcorrer do período considerado neste trabalho. No início do período, foi dada ênfase para avaliação dos resultados dos projetos curriculares. O crescimento das críticas ao modelo experimental, quantitativo, influenciado pela linha psicometrista, gradualmente levou à adoção de novos paradigmas de pesquisa. Passouse a obter dados com observação direta, estudo de documentos, entrevistas com os componentes e usuários dos projetos curriculares, alunos, professores, administradores em projetos de pesquisa quantitativa. Dentro dessa linha básica, foram usadas medidas qualitativo-fenomenológicas, processos etnográficos, naturalísticos, pesquisa participante, estudos de caso, entre outros.

O debate entre os que defendem a linha por muitos chamada experimental, que exige dados quantitativos, e os que preferem uma linha naturalística, que apresenta o processo educacional em toda a sua complexidade de intrincadas relações, está longe de ser encerrado. Apesar desse esforço que levou à criação de grupos de pesquisa em vários pontos do país, a maioria deles gerada pelos pesquisadores formados nos núcleos iniciais, os resultados das pesquisas ainda não atingiram os centros de decisão, nos âmbitos federal, estadual e municipal, para influir decisivamente na preparação e avaliação de currículos, nos projetos de aperfeiçoamento de docentes e nas relações entre os elementos que interagem nas escolas. Os professores em classe ficam cada vez mais afastados tanto do centro de decisões políticas como dos centros de pesquisa.

Sem usar as informações de pesquisas prospectivas que coletem dados para evitar esforços e desperdícios, as propostas de reforma têm sido irrealistas ou inaceitáveis pelos professores que finalmente são os responsáveis pelas ocorrências em sala de aula. É tarefa urgente encontrar um meio termo adequado entre os dois extremos: um das organizações centrais trabalhando de forma isolada e outro que deixa a responsabilidade sobre as decisões curriculares exclusivamente à escola e aos docentes. Se, por um lado, é imprescindível a intensificação das relações entre a escola e a comunidade para a formação de cidadãos atuantes, por outro, é absurdo ignorar o que têm a dizer os cientistas e pesquisadores e o que se conhece hoje sobre os processos de reforma curricular.

Os parâmetros curriculares fartamente distribuídos, na tentativa de produzir mudanças, usaram muito pouco o considerável montante de informações existentes sobre mudanças do ensino de Ciências. Os cientistas e pesquisadores foram alijados da produção de documentos que vêm levantando controvérsias entre os especialistas e dificuldades para os docentes. Caberá aos cientistas influir colaborando para formular propostas curriculares atualizadas, relevantes e realistas, não só indicando as impropriedades, omissões e propostas discutíveis, mas também propondo linhas de trabalho, sugestões para reformulação, mudanças e substituição. Merecem também uma análise detida para uso mais profundo e abrangente dos dados obtidos nos inúmeros processos de avaliação empreendidos pelo Inep e pelos sistemas de várias unidades da federação para que sejam identificados os pontos necessitados de intervenção como orientação para melhorar o processo educativo em todos os níveis e a confecção dos planos nacional e estaduais de educação. Não cabe mais um trabalho isolado, de gabinete dos legisladores oficiais. Ao contrário, será necessário angariar a participação e adesão da sociedade em seus múltiplos segmentos, para que as declarações de intenção propostas não soneguem a 
liberdade de ação das instituições, deixando o sistema à mercê dos slogans em voga que refletem as políticas vigentes.

\section{REFERÊNCIAS BIBLIOGRÁFICAS}

AAAS - American Association for the Advancement of Science. Project 2061 Science for all americans. Washington, 1989.

ALVES, N. (org.). Múltiplas leituras da nova LDB: Lei de Diretrizes e Bases da Educação Nacional (Lei n. 9.394/96). Rio de Janeiro, Quality Mark, 1997.

BRASIL. Lei n. 4.024 de 20/12/1961: fixa as diretrizes e bases da Educação Nacional. São Paulo, FFCL, 1963.

. Diretrizes e bases da educação nacional: Lei n. 5.692, de 11/8/1971, Lei n. 4.024, de 20/12/1961. São Paulo, Imesp, 1981.

. Ministério da Educação e do Desporto. Secretaria do Ensino Fundamental. Parâmetros curriculares nacionais para o ensino fundamental: documento introdutório. Brasília, MEC, 1995.

. Lei n. 9.394 Diretrizes e bases da educação nacional: promulgada em 20/12/1996. Brasília, Editora do Brasil, 1996.
Secretaria de Ensino Fundamental. Parâmetros curriculares nacionais. Brasília, MEC, v.10, 1997.

DUIT, R. e TREAGUST, D. "Learning in science: from behaviourism towards social constructivism and beyond". International Handbook of Science Education. Boston, Kluwer Academic Publisher, 1998.

GROSS, B. e GROSS, R. (eds.). The great schools debate. New York, Simon \& Schuster Inc., 1985.

INSTITUTO NACIONAL DE ESTUDOS E PESQUISAS EDUCACIONAIS Avaliação de concluintes do ensino médio em nove estados, 1997: relatório final. Brasília, 1998 (Anexo 2).

. Avaliação de concluintes do ensino médio em nove estados, 1997: relatório síntese. Brasília, 1998.

KNAPP, M.S. "Between systemic reform and the mathematics and science classroom: the dynamics of innovation, implementation and professional learning". Review of Educational Research. New York, v.67, n.2, 1997, p.227-226.

KRASILCHIK, M. O professor e o currículo das ciências. São Paulo, EPU/Edusp, 1987.

PESTANA, M.I. de S. et alii. SAEB 97: primeiros resultados. Brasília, Inep, 1999.

TIMPANE, M. e WHITE, L.S. (eds.). "Reforming science, mathematics and technology education". Higher education and school reform. San Francisco, Jossey - Bass publishers, 1998. 